\title{
O CONCEITO DE EXPERIÊNCIA EM BENJAMIN: CONSIDERAÇÕES ANALISANDO AS DIRETRIZES CURRICULARES NACIONAIS PARA A FORMAÇÃO DE PROFESSORES DE EDUCA- ÇÃO BÁSICA E DE PROFESSORES DE EDUCAÇÃO FÍSICA ${ }^{1}$
}

\author{
Cristiano Mezzaroba \\ Universidade Federal de Santa Catarina, Florianópolis, Santa Catarina Brasil \\ Santiago Pich \\ Universidade Federal de Santa Catarina, Florianópolis, Santa Catarina Brasil
}

\begin{abstract}
Resumo
O texto compreende uma discussão teórico-conceitual em torno do conceito de experiência em Walter Benjamin e uma análise documental de documentos brasileiros que se ocupam da formação de professores - as Diretrizes Curriculares Nacionais para a formação de professores de Educação Básica e também as Diretrizes Curriculares Nacionais para a formação de professores de Educação Física (EF). Esses documentos foram inventariados procurando-se analisar/desvelar como eles abordam a perspectiva de se pensar a formação profissional a partir da experiência com os saberes/fazeres do campo da EF, em que se observa uma ênfase nas dimensões técnica e prática na formação desses profissionais, entendida como competências a serem desenvolvidas e pautada numa racionalidade técnica.
\end{abstract}

Palavras-chave: Experiência. Walter Benjamin. Diretrizes Curriculares Nacionais. Formação de professores de Educação Física.

THE CONCEPT OF EXPERIENCE IN BENJAMIN: CONSIDERATIONS WHEN ANALYZING THE NATIONAL CURRICULUM GUIDELINES FOR THE TRAINING OF BASIC EDUCATION AND PHYSICAL EDUCATION TEACHERS

\begin{abstract}
The text includes a theoretical-conceptual discussion about the concept of experience in Walter Benjamin and an analysis of Brazilian documents that deal with teachers' education - the National Curriculum Guidelines for the training of Basic Education teachers and also the National Curricular Guidelines for the formation of Physical Education (PE) teachers - which were searched seeking to analyze/reveal how they point to the perspective of thinking about vocational training based on the experience with knowledge/know-how in the field of PE. In this field there is an emphasis on the technical and practical dimensions of these professionals' training, understood as competences to be developed, based on a technical rationality.
\end{abstract}

Keywords: Experience. Walter Benjamin. National Curriculum Guidelines. Teachers' training in Physical Education.

\footnotetext{
${ }^{1}$ O presente trabalho não contou com apoio financeiro de nenhuma natureza para sua realização.
} 


\section{EL CONCEPTO DE EXPERIENCIA EN BENJAMIN: CONSIDERACIONES ANA- LISANDO LAS DIRECTRICES CURRICULARES NACIONALES PARA LA FOR- MACIÓN DE PROFESORES DE EDUCACIÓN BÁSICA Y DE PROFESORES DE EDUCACIÓN FÍSICA}

\section{Resumen}

El texto comprende una discusión teórico-conceptual en torno al concepto de experiencia en Walter Benjamin y un análisis documental de documentos brasileños que se ocupan de la formación de profesores - las Directrices Curriculares Nacionales para la formación de profesores de Educación Básica y también las Directrices Curriculares Nacionales para la formación de profesores de Educación Física (EF) - los cuales fueron inventariados buscando analizar/desvelar cómo esos mismos documentos apuntan la perspectiva de pensar la formación profesional a partir de la experiencia con los saberes/haceres del campo de la EF, en que se observa un énfasis en las dimensiones técnica y práctica en la formación de estos profesionales, entendida como competencias a ser desarrolladas, pautada en una racionalidad técnica.

Palabras clave: Experiencia. Walter Benjamin. Directrices Curriculares Nacionales. Formación de profesores de Educación Física.

\section{Introdução}

Palavra em voga atualmente, experiência tem sido utilizada nos mais diversos campos da vida humana para expressar algum acontecimento ou experimento significativo. O termo, oriundo do latim experientia e do verbo experiri, significando experimentar, pode denotar o ato ou efeito de experimentar-se, uma experimentação; também pode ser considerado como algo relacionado com uma prática da vida; uma habilidade, uma prática que vai sendo adquirida ao longo de uma profissão, arte ou ofício; uma experimentação, algo que nos é transmitido pelos sentidos; uma forma de conhecimento (AURÉLIO, 2004).

Aqui nos interessa a compreensão do termo a partir daquilo que o filósofo alemão Walter Benjamin refletiu quanto às possíveis compreensões relacionadas com experiência. Trata-se, também, da denúncia do esfacelamento da experiência na modernidade, e das transformações que vão ocorrendo numa sociedade que mostra seus limites e seus perigos (LIMA; BAPTISTA, 2013; PAGNI; GELAMO, 2010).

Neste texto, caracterizado metodologicamente como uma análise documental, tem-se o problema de refletir e analisar as possibilidades de pensar a experiência na formação do professor na atualidade, ou seja, em relação à experiência formativa e profissional, que pode ser problematizada considerando os princípios gerais perspectivados no campo da formação de professores, em especial, dos professores de Educação Física (EF). Perguntamo-nos: é possível que um modo de relação com os saberes do campo, bem como uma forma nova de entender esses próprios saberes possibilitem fazer experiência? Um determinado tipo/conjunto de saberes/práticas pode garantir uma experiência formativa que abranja uma multiplicidade de temas e formas de reflexão e mediação?

Será esse o nosso exercício de análise e reflexão, em que, pensando algumas formulações quanto ao conceito de experiência em Benjamin, inventariamos e discutimos dois documentos elaborados pelo Ministério da Educação brasileiro: as Diretrizes Curriculares Nacionais para a Formação de Professores de Educação Básica, DCNEB (BRASIL, 2002), e as Diretrizes Curriculares Nacionais para os cursos de graduação em EF, DCNEF, em nível superior de graduação plena (BRASIL, 2004).

Nesses documentos, inventariamos o aparecimento ou compreensão do termo experiência, no intuito de problematizar o modo como tal tema tem sido veiculado no âmbito da 
formação de professores no Brasil. Assim, partimos dos seguintes pontos: a experiência aparece nos documentos selecionados? De que forma e com que significados aparece? Em que contexto(s)? Que relação há entre a experiência e a forma de se acessar o conhecimento?

Na sequência do texto, apresentamos os elementos teóricos pertinentes à construção de um possível conceito de experiência em Benjamin. Em seguida, inventariamos os documentos já enunciados. Ao final, procura-se resgatar as reflexões presentes, pensando o lugar da experiência na formação de professores de EF.

\section{Elementos teóricos sobre a experiência}

O autor de referência para a elaboração do conceito de experiência é Walter Benjamin, filósofo berlinense, para quem esse conceito era um vetor constitutivo da sua obra, tanto nos escritos de juventude, como nos de maturidade. Para sua apropriação, nos valemos da ideia de que neles pode ser observado um duplo movimento. Por um lado, de permanência de um núcleo de sentido, qual seja, a ideia de que na modernidade se observa uma perda de experiência, que está pautada pela primazia, na vida do homem moderno, da "vivência" (Erlebnis), em detrimento da "experiência" (Erfahrung). O primeiro termo pressupõe um modo de relação com a vida, no qual a subjetividade é formatada, massificada, de modo a não poder vir-a-ser enquanto singularidade, a partir da sua relação com o Outro. O segundo pressupõe um modo de viver no qual os sujeitos se encontram sempre em relação de afetação com a vida, portanto com o Outro e o mundo. Por outro lado, entendemos que a partir das diversas influências teóricas do autor, o conceito é reelaborado, criando assim uma constelação semântica em torno dele.

Em fragmento escrito em 1913 (revisitado em 1929), Benjamin escreve brevemente sobre a "Experiência" ao mobilizar seu argumento - e a força da juventude - contra a palavra experiência, que acabou sendo, na sua curta trajetória, o que ele mesmo considerou ser "um elemento de sustentação em muitas de minhas coisas". (BENJAMIN, 2009, p. 21). Neste texto, ele já apresenta uma primeira elaboração do par que posteriormente será consagrado: vivência - experiência. Sendo a primeira a forma de vida do adulto, do "filisteu", isto é, daquele que vive a religião (e a vida) somente de maneira formal, não implicando-se nem ética, nem esteticamente a ela (não dando forma a ela, como um artista a uma obra da arte, mas replicando de maneira meticulosa, fria e intolerante o modelo original). Portanto, uma forma de vida à qual o jovem, ao crescer, curva-se, conforma-se. Por outro lado, a "verdadeira experiência", a da juventude, é tratada como um modo de relação com a vida e não somente, nem primariamente, como algo vinculado a uma "fase" da vida humana. Modo esse centrado na ideia da vida como algo que está sempre em potência, sempre em aberto, sempre sendo, contingente; e que não é uma mera potência a ser realizada no ato da forma de vida adulta, da vida filisteia.

No texto escrito em 1917, Sobre el programa de la filosofia futura, Benjamin (1991), tendo como principal referência de crítica as críticas kantianas, trata de alguns limites para a ciência como um estágio último do conhecimento. Segundo seu pensamento, a filosofia vindoura precisa pensar num novo conceito de conhecimento, de experiência e de verdade. Para ele, a ideia basilar da filosofia por vir está na linguagem, não como mera mediação, mas como constituinte de formas novas/outras de acessar saberes, conhecimentos. Isto seria um elemento balizador de uma ideia de experiência superadora do conceito kantiano. Ainda, vale lembrar que em dois textos chaves para este debate, um sobre o problema do conhecimento, e o segundo sobre a filosofia da linguagem, (BENJAMIN, 2012a), o filósofo berlinense assinala que uma vez que a linguagem dos homens não permite a apreensão da coisa em si, por ser uma linguagem pós-edênica, abre-se a possibilidade da verdade ser sempre dita e apresentada (e não representada). Na linguagem, portanto, como algo que comunica uma comunicabilidade, estaria esse grau de abertura, e isso caracterizaria uma forma não instrumental de se relacionar com o mundo, abrindo a possibilidade de fazer experiência. 
Em outro texto clássico, porém neste momento já sob a influência do materialismo histórico-dialético, Experiência e pobreza (BENJAMIN, 2012a), há a denúncia e análise sobre o fato de as ações de experiências estarem em declínio na modernidade. Nesse escrito, ele argumenta sobre o desenvolvimento da técnica, que, ao invés de trazer progresso, gerou miséria, uma condição tal que, pelo império da técnica, assentada na racionalidade instrumental, tornou-se impossível a relação com o Outro a partir da palavra inscrita no movimento da tradição.

Essa pobreza de experiência não se refere ao âmbito particular, individual, e sim à pobreza da humanidade, na sua coletividade. Nas suas palavras, Benjamin destaca:

\begin{abstract}
Sim, confessemos: essa pobreza não é apenas pobreza em experiências privadas, mas em experiências da humanidade em geral. Surge assim uma nova barbárie. [...] Ela [a barbárie] o impele [o sujeito] a partir para a frente, a começar de novo, a contentar-se com pouco, a construir com pouco, sem olhar nem para a direita nem para a esquerda. (BENJAMIN, 2012a, p. 124-125).
\end{abstract}

Benjamin (2012a), de certo modo, nos chama atenção para essa transição para uma sociedade de massa, em que a produção dessas subjetividades também ocorre de forma massificada, impactando na forma com que cada um de nós, e de toda nossa coletividade, passa (ou deixa de passar) por experiências verdadeiramente significativas.

Em um texto clássico sobre o problema da experiência, $O$ narrador - Considerações sobre a obra de Nikolai Leskov (2012b), escrito entre 1936 e 1937, Benjamin (2012b) retoma e amplia o problema do texto anterior. Uma dessas perdas denunciadas por Benjamin (2012b) refere-se à tradição da linguagem narrativa e da figura do narrador. $\mathrm{Na}$ original análise benjaminiana da relação entre a linguagem e o modo de produção do capitalismo industrial, a produção maquinal em série tem implicações no sentido de que a palavra deixa de ser artesanalmente produzida, enraizada na vida e na tradição, para ser produzida em série, na lógica da informação e sem relação com tradição alguma, mas na solidão do indivíduo, no romance. Ao propor emitir um discurso uniforme e homogêneo, os veículos comunicacionais, com a informação de massa, explicitam os perigos da narração moderna/contemporânea. Um desses perigos, sob a perspectiva de Benjamin (2012b, p. 219), se dá pelo fato de a informação aspirar "a uma verificabilidade imediata". Outro perigo se verifica na constatação de que "a informação só tem valor no momento em que é nova. Ela só vive nesse momento, precisa entregar-se inteiramente a ele e sem perda de tempo tem que se explicar nele." (BENJAMIN, 2012b, p. 220).

O filósofo berlinense considera que a narrativa pressupõe uma presença corporal no mundo, e a marca que o narrador imprime quando narra emerge do corpo. Essa experiência de narrar é aquela própria da cultura oral, realizada pelos narradores: "A experiência que passa de boca em boca é a fonte a que recorreram todos os narradores." (BENJAMIN, 2012b, p. 214). O narrador, então, seria esse "[...] homem que sabe dar conselhos ao ouvinte" (BENJAMIN, 2012b, p. 216), o que vem se perdendo hoje em dia, pois soa "[...] como algo antiquado, isto se deve ao fato de as experiências estarem perdendo a sua comunicabilidade." (BENJAMIN, 2012b, p. 216). Outro efeito, bastante perigoso para a transmissão geracional que poderia configurar-se em experiências de ouvir, refere-se ao processo de assimilação, ou seja, ao fato de que, sem narrador presente, algo ocorre na memória daquele que uma vez ouvia/prestava atenção ao que era narrado: "desaparece o dom de ouvir" (BENJAMIN, 2012b, p. 221). Para narrar, é necessário, primeiro, ouvir! Conforme Benjamin (2012b), isso altera percepções de memória, o que se relaciona, diretamente, com a forma de sofrer experiências. Para Benjamin, portanto, memória e experiência são dois lados de uma mesma moeda, relacionam-se e referem-se à rememoração. Assim, a narração implica uma singularidade de quem narra e pressupõe, também, uma produção dessa narrativa. Eis, ao nosso ver, um quarto 
pressuposto do que podemos entender como experiência em Benjamin: a experiência é aquilo que passa e atravessa o indivíduo, sendo incorporado em sua história de vida, algo que se define em "primeira pessoa", o que significa pensar o sujeito numa história social. Desse modo, a experiência em Benjamin pressupõe o emergir de algo que não pode ser controlado, nem determinado pelo sujeito, situando-se na esfera da contingência e do acontecimento,

A partir das colocações acima, que desdobramentos podem emergir para pensar a formação humana, e, particularmente, a formação de professores da EF? Algumas problematizações nos parecem possíveis: o sistema formal de ensino, especialmente no ensino superior a partir das suas diretrizes oficiais, opera com um modelo identitário do que "deve vir a ser" o professor de EF ou se pauta pela criação dessa ideia no processo de devir-professor? Como é pressuposto o lugar da palavra e do movimento humano (ou da linguagem corporal) no processo formativo? Palavra e movimento assumem o lugar de espaços de produção de sentidos a partir da relação do sujeito com o Outro, ou de transmissão de informações tecnicamente produzidas?

\section{Inventariando dois documentos educacionais brasileiros}

\section{a) DCNEB - RESOLUÇÃO CNE/CP, 18/02/2002 (BRASIL, 2002)}

O termo experiência aparece apenas uma vez, no Art. $6^{\circ}, \S 3^{\circ}$, item VI, o qual explana sobre o que se espera quanto às competências para além da formação específica do futuro professor no debate contemporâneo, em que sejam considerados alguns itens, dentre eles, o sexto item, o "conhecimento advindo da experiência." (BRASIL, 2002, p. 3). Poderíamos nos perguntar, para aprofundar as reflexões: que experiência seria essa? Anterior ao curso de formação? Oportunizada apenas pelo curso? Ou, ainda, aquela experiência que virá depois, decorrente do tempo de experiência com as práticas cotidianas? Supomos que essa experiência tenha uma conotação, segundo o referido documento, bastante restrita ao âmbito da prática.

O que chama atenção na referida resolução é quanto ao uso intenso do termo competência, o qual é mencionado 23 vezes nas 7 páginas do documento, o que revela, claramente, uma forte influência das "competências" nos cursos de formação. Vê-se, aí, certamente, a influência do pensamento do pesquisador francês Philippe Perrenoud no contexto brasileiro de formação de professores. Sua obra - Dez novas competências para ensinar, publicada em 1999, e no Brasil no ano seguinte - teve grande divulgação e penetração no contexto pedagógico brasileiro, podendo também ter influenciado aqueles que sugeriram/escreveram o documento que está aqui sendo inventariado, ou seja, as DCNEB. Ficam alguns questionamentos: seria possível associar a "competência" com a "experiência" enquanto eixos pensados e articulados para a formação de um professor? Certamente articular uma à outra, à primeira vista, não pode ser feito pensando exclusivamente na questão da prática pedagógica entendida apenas como "experimentação".

O que se percebe - se podemos arriscar inferir isso - é uma ênfase em uma formação técnica que visa à excelência didático-pedagógica pautada numa palavra: competência. Segundo tal documento, a formação desses professores deve ser pautada numa lógica de eficiência e certeza que, sabemos, não configura esse campo formativo, já que ele é influenciado por aspectos plurais e complexos, portanto, incertos. É uma formação, um preparo fortemente influenciado numa concepção de um sujeito (um "especialista", [BRASIL, 2002 , p. 5, Artigo $9^{\circ}$ ]) que deve ser (bem) preparado para o trabalho, competente para transferir conhecimento (técnico) aos alunos posteriormente. Nos termos deste documento, deve-se ter o "domínio" do conhecimento pedagógico (BRASIL, 2002, p. 3, Artigo 6º $)$ 
Associando-se aos pressupostos benjaminianos de experiência, seria a calculabilidade com fins certeiros, eficazes e eficientes que faria esse "sujeito da educação" garantir sua profissionalidade e atingir sua intencionalidade, sem a consideração de fatores contingenciais e com a quase certeza de uma uniformidade por parte dos seus "alunos aprendentes"? Seria essa a reflexão possível nesse exercício de pensar o par educação e experiência em Benjamin a partir desse documento em questão? Há uma desconsideração, no documento, quanto às questões contingenciais e imprevisíveis nas experiências dos sujeitos, tanto dos professores, como dos alunos?

Um exemplo disso pode ser explicitado pelo que consta no Artigo $4^{\circ}$, item IV (BRASIL, 2002), ao associar que os conteúdos a serem ensinados estão articulados com didáticas específicas. Quanto ao domínio do conhecimento pedagógico, seria a experiência a incorporação de uma mera técnica didático-pedagógica? Não seria reducionismo pensar a formação sob tal ponto de vista?

A própria ideia de especificidade impede, certamente, a abordagem para o "todo", o que gera, automaticamente, um empobrecimento da experiência na formação.

Há, também, neste sentido, aspectos vazios na descrição do documento, como por exemplo no Artigo $4^{\circ}$, item III, em que se sugere que, no desenvolvimento dos cursos de formação, "a seleção dos conteúdos das áreas de ensino da educação básica deve orientar-se por ir além daquilo que os professores irão ensinar nas diferentes etapas da escolaridade" (BRASIL, 2002, p. 2). Quando no parágrafo único deste mesmo artigo se considera que a "aprendizagem deverá ser orientada pelo princípio metodológico geral" (BRASIL, 2002, p. 2) também se vê isso. Outro exemplo quanto ao uso de termos vazios de sentido refere-se ao Artigo $7^{\circ}$, em relação à autonomia: "a formação deverá ser realizada em processo autônomo, em curso de licenciatura plena, numa estrutura com identidade própria" (BRASIL, 2002, p. 4). Poderíamos nos perguntar: o que o documento está entendendo por autonomia? Aprender, dominar e incorporar competências específicas a uma profissão significa automaticamente ser um "profissional autônomo"?

A formação dos professores, pelo que consta nessas diretrizes, torna-se um "preparo" para a "prática". Esses dois termos, aqui colocados propositalmente entre aspas, podem ser deslocados do documento e pensados enquanto documento que traça princípios, fundamentos e procedimentos para o que se almeja quanto à formação dos professores brasileiros. Em relação ao termo "preparo", o Artigo $3^{\circ}$ assim espera quanto à formação desses professores: "A formação de professores que atuarão nas diferentes etapas e modalidades da educação básica observará princípios norteadores desse preparo para o exercício profissional específico". (BRASIL, 2002, p. 2).

Quanto ao termo "prática", o Artigo 4", ao elencar o que é fundamental que se busque nos cursos de formação, em seu parágrafo único, assim explicita: “A aprendizagem deverá ser orientada pelo princípio metodológico geral, que pode ser traduzido pela ação-reflexão-ação e que aponta a resolução de situações-problema como uma das estratégias didáticas privilegiadas." (BRASIL, 2002, p. 3). Pode-se inferir que a experiência novamente está sendo reduzida tendo o "fazer" como ênfase, ou seja, a experiência na sua dimensão estritamente prática! Também nos Artigo $12^{\circ}$ e $13^{\circ}$ os aspectos relacionados à "prática" são enfatizados, como, por exemplo: que ela não poderá ser reduzida ao estágio e desarticulada do curso; que deverá estar presente do início ao fim do curso; que todas as disciplinas deverão ter sua dimensão prática; que deve haver a perspectiva interdisciplinar quanto à dimensão prática; que prática deve ser tratada como observação e reflexão e que as tecnologias da informação podem enriquecer a dimensão da prática.

Assim, neste sentido, em relação à "prática" e aos aspectos citados acima, oriundos deste documento em análise, será que não deveríamos pensar que a "prática" é algo muito mais complexo do que, simplesmente, assumir uma turma e fazer uma transposição didática? 
Contreras (2012, p. 121), ao tratar da perspectiva do "professor reflexivo" de Donald Schön, comenta que para este autor, a partir da reflexão na ação, enquanto sujeito que investiga no contexto da prática, se "constrói uma nova maneira de observar o problema". Podemos inferir que há nisso uma certa ênfase nas questões práticas, também bastante presente no documento em análise. A prática, isoladamente, não dará conta de colocar e responder os problemas daqueles que atuam e pesquisam no ambiente escolar. Não será possível avançar numa formação mais sólida, atualizada, crítica, reflexiva e autônoma - palavras e adjetivos comumente relacionados à formação de professores na atualidade - se apenas colocarmos como "ordem do dia" uma formação construída pelas/para as questões práticas.

Uma observação quanto às DCNEB é sobre o quanto o documento destaca os aparatos instrumentais e técnicos, na forma de espaços específicos, como laboratórios, bibliotecas, bem como os recursos tecnológicos de informação e comunicação. Isso consta no Artigo $2^{\circ}$, em que se prevê o preparo para "o uso das tecnologias da informação e da comunicação e das metodologias, estratégias e materiais de apoio inovadores" (BRASIL, 2002, p. 1, Item VI); bem como no Artigo $7^{\circ}$, onde consta que "as escolas de formação garantirão, com qualidade e quantidade, recursos pedagógicos como biblioteca, laboratórios, videoteca, entre outros, além de recursos de tecnologias da informação e da comunicação" (BRASIL, 2002, p. 4, Item VII).

Por último, e pensando que experiência pressupõe uma relação de "criação", poderíamos refletir a respeito da impossibilidade dessa criação diante de uma normatividade que, sabemos, não se configura em sua totalidade no dia a dia pedagógico e no dia a dia formativo. Apesar de entendermos que o conceito moderno de educação pressupõe a intencionalidade e a previsibilidade - os próprios documentos em análise são produtos desse processo -, não podemos deixar de considerar que o desafio na educação é a possibilidade de abertura e potência que ela possibilita, sem desconsiderar ou desvalorizar sua intencionalidade. Em geral, a contingência da experiência, que permite o imprevisível, o duvidoso, o aberto, o incerto, o inseguro, o não-definitivo não está contemplada nas diretrizes, o que se entende: o documento procura orientar um conjunto de agentes e instituições para que haja uma formação "mais sólida" desses agentes educacionais. Entretanto, há que se considerar que na própria prática, ou nas próprias competências, fazendo-se uso do termo recorrente no documento analisado, há o imprevisível, sempre à espreita, atuando. Talvez este seja o "ponto de fuga", o "resto", o que "sobra" diante de uma normatividade heterônoma, enquanto espaço de ação para os sujeitos que se dedicam às ações pedagógicas.

Por mais que haja uma previsibilidade na formação - via diretrizes, via currículos, via disciplinas, entre outros documentos e cerceamentos -, sabemos que não se colocam os sujeitos em formas pré-definidas e ao final de um processo tem-se uma homogeneização de profissionais.

Portanto, finalizando essas reflexões sobre as DCNEB, vimos um entendimento esvaziado do que se entende por experiência, havendo uma ênfase na dimensão prática, reduzindo ainda mais o saber teórico enquanto tradição de um campo do conhecimento. Elas parecem conformar apenas um modus operandi, não de um conhecimento humano, mas de uma técnica (corporal, gestual, oral, didática, pedagógica, científica) que permite a eficiência na transmissão de um saber. Seria esse, então, o empobrecimento da experiência na formação de professores?

\section{b) DCNEF - RESOLUÇÃO Nº 7, 31/03/2004 (BRASIL, 2004)}

Entendendo que a EF é uma área do conhecimento e de intervenção acadêmicoprofissional que tem o movimento humano como seu objeto de estudo e de intervenção, tais DCNEF: 
definem os princípios, as condições e os procedimentos para a formação de profissionais de Educação Física, [...] para aplicação em âmbito nacional na organização, no desenvolvimento e na avaliação do projeto pedagógico dos cursos de graduação em Educação Física nas Instituições do Sistema de Ensino Superior. (BRASIL, 2004, p. 1).

O que se espera, na formação deste profissional, é uma formação generalista, humanista e crítica, em que o professor possa analisar criticamente a realidade social e possa contribuir para o enriquecimento cultural das pessoas, cujo fim seria "aumentar as possibilidades de adoção de um estilo de vida fisicamente ativo e saudável.” (BRASIL, 2004, p. 2). Entretanto, para se chegar a esse objetivo, que experiências formativas seriam essas? Haveria, então, um discurso homogêneo e hegemônico que garanta um único modo de vida - padronizado - para que cada ser humano, respeitando-se sua individualidade, sua singularidade, seus modos próprios de vida, tenha, com isso, um "estilo (único) de vida" que sirva para todo o conjunto da população? Se a experiência também pressupõe singularidade, há, aqui, uma tentativa de formatação do conjunto populacional no sentido de padronização, impossibilitando, assim, a experiência no sentido benjaminiano. Também, seria oportuno perguntar-nos se o sistema de ensino, tal como se organiza, comporta a experiência ou se ela seria uma categoria interessante para questionar a organização e o modo de operar de tal sistema.

O termo experiência aparece 4 vezes, e o termo vivência ("vivenciada", "vivenciar") aparece outras 3 vezes. Novamente o termo "competência" aparece com certa frequência, o que evidencia uma relação entre esses dois documentos. Há, assim, como podemos constatar, uma correlação na normatividade, se pensarmos o documento anterior como algo mais geral, a este, agora, mais específico.

Também se evidencia uma certa mecanização discursiva, quando no Artigo $6^{\circ}, \S^{\circ}$, descrevem-se alguns itens "visando a aquisição e desenvolvimento" de competências e habilidades (BRASIL, 2004, p. 2). O primeiro deles inicia com: "Dominar os conhecimentos conceituais, procedimentais e atitudinais específicos da Educação Física e aqueles advindos das ciências afins" (BRASIL, 2004, p. 2). Questiona-se: se o próprio conhecimento é mutável, esse "domínio" sugerido pelas DCNEF em tela pode ser conseguido num tempo destinado a uma formação profissional? Que experiência formativa seria essa em que se espera (e se enfatiza) o domínio técnico? Outro exemplo situa-se no Artigo $10^{\circ}, \S 3^{\circ}$, ao tratar das atividades complementares: "As atividades complementares deverão ser incrementadas ao longo do curso, devendo a Instituição de Ensino Superior criar mecanismos e critérios de aproveitamento de conhecimentos e de experiências vivenciadas pelo aluno" (BRASIL, 2004, p. 5). Por mais que se pareça uma flexibilização, não seria um recurso para se diminuir ainda mais o tempo de possíveis experiências formativas?

Ainda em relação à formação específica, obviamente que se trata de uma formação reduzida. Neste sentido, as experiências também são reduzidas, tanto em relação à questão temporal, como, também, no âmbito das diversas formas de experiência. Assim, que professor é este que estará em processo de formação? Que experiências são essas que ele terá, tanto na sua formação, como na sua atuação, logo mais? É interessante observar que o referido documento destina $20 \%$ da carga horária total do curso de formação para experiências ligadas a núcleos temáticos de aprofundamento. É possível simplesmente deslocar uma experiência dentro de uma previsibilidade temporal com início e fim pré-programados?

Há uma contradição quando observamos o Artigo $10^{\circ}$, o qual está assim escrito: "A formação do graduado em Educação Física deve assegurar a indissociabilidade teórico-prática por meio da prática como componente curricular, estágio profissional curricular supervisionado e atividades complementares" (BRASIL, 2004, p. 5). Por que a contradição? Porque apesar de utilizar o termo "indissociabilidade teórico-prática", há ênfase, na sequência da frase, às 
questões práticas (estágio, atividades, prática curricular). Igual situação encontramos no outro documento, nas DCNEB (BRASIL, 2002). Se ao professor sempre coube - e sempre houve essa representação - "intelectualidade", por que vemos tamanha ênfase nas questões de aplicabilidade prática dos aspectos didático-pedagógicos em detrimento dos aspectos teóricos, conceituais e intelectuais? Um professor deve ser "preparado" e "formado" apenas para ser um prático, que não pensa, que não sabe, mas que aplica conhecimentos e metodologias prévias? Que experiências docentes seriam essas? Para qual conhecimento? Para qual público? Com quais fins?

Também nessas DCNEF detectamos incompatibilidades entre a possível experiência no sentido benjaminiano e a normatividade presente pelo peso das palavras, em especial, a questão das competências e da ênfase numa "prática" para os professores de EF em formação. Haveria, assim, um empobrecimento dessas experiências quando se normatiza um saber prático sobre um saber teórico, ainda mais numa área que, tradicionalmente e historicamente, foi povoada por um discurso eminentemente prático e que dava pouca importância à reflexão e a considerações teóricas? Se a experiência é aquilo que passa e afeta o sujeito, para o futuro professor de EF, então, essas experiências serão apenas as de ordem "práticas"? Uma formação que prioriza a razão instrumental, portanto pautada pela calculabilidade da vida, pode ser considerada uma experiência formativa?

\section{Considerações finais}

Arriscamo-nos a dizer que pelos pressupostos do conceito benjaminiano de experiência, há uma dificuldade em encontrar possibilidades para que ela se realize a partir de documentos oficiais que estão apontando para uma ênfase na dimensão técnica e prática, entendida como "competências" a serem ensinadas. Reduz-se uma potencialidade humana a uma calculabilidade da técnica didático-pedagógica com fins de transmissão de saberes/conhecimentos científicos e culturais.

Entendemos, também, que talvez nunca tenha havido um "tempo de ouro" em relação à formação de professores, mas certamente elementos de uma tradição professoral, importantes à constituição de um ethos e um habitus profissional, vinculados a fundamentos teóricos/filosóficos, não podem ser perdidos dando espaço quase que exclusivo e enfático às questões práticas e técnicas de uma formação. Se for assim, e se seguirmos neste ritmo, estaremos confundindo um professor com um mero executor de atividades pensadas por alguém. Preencher os currículos escolares e universitários de conteúdos, com pouca profundidade e entendimento sócio-filosófico, garante uma experiência com os saberes a ponto de "formar" um cidadão? $\mathrm{O}$ acesso e o uso das tecnologias na educação não se configuram como um "discurso salvador" do campo formativo?

Talvez o indicativo para superar essa "pobreza na experiência" contemporânea em "formar-se professor" esteja no retorno aos pressupostos benjaminianos, primeiramente, recuperando a comunicabilidade professoral, especialmente no sentido de ouvir. Ouvir no sentido de prestar atenção às coisas do mundo, ao que já foi produzido, ao que está impresso nos livros, nas concepções de autores/autoras diversos/as. Há uma tradicionalidade que tem uma eficácia simbólica e que, portanto, não se perde, mas se transforma, e que não pode ser esquecida no âmbito de uma formação docente.

Uma educação que permite experiência, então, não pode ser algo tão cronometrado como a que temos, com a ideia de um caminho reto, seguro, definitivo. Pautar uma crítica a esse tempo que vivemos se mostra como o começo para se possuir experiência na modernidade, compreendendo seus códigos, suas normas, seus valores sociais/morais etc. Talvez entender processos singulares e contingenciais em meio a uma vida normativa que cada vez se apresenta e se intensifica seja a maneira de considerar as possibilidades de experiência na for- 
mação docente, tendo o corpo como centralidade (como a materialidade que é afetada pelo mundo), tendo uma educação que permita o acontecimento (e não apenas sua reprodução), uma mediação em forma de linguagem adequada, valorizando a potência dessa linguagem e não apenas seu caráter instrumental.

\section{Referências}

BENJAMIN, W. Sobre el programa de la filosofía venidera. In: Sobre el programa de la filosofía futura $\mathbf{y}$ otros ensayos. Madri: Taurus, 1991. Disponível em: $<$ http://grietaenelmuro.wordpress.com/2010/08/08/sobre-el-programa-de-la-filosofiavenidera-walter-benjamin/>. Acesso em: 20 abr. 2015.

. Experiência. In: . Reflexões sobre a criança, o brinquedo e a educação. 2. ed. São Paulo: Duas Cidades; Editora 34, 2009.

. Sobre arte, técnica, linguagem e política. Lisboa: Relógio D’Água, 2012a. se, $2012 b$.

Obras escolhidas I: magia e técnica, arte e política. 8. ed. rev. São Paulo: BrasilienBRASIL. Ministério da Educação. Conselho Nacional de Educação. Resolução CNE/CP n. 1, de 18 de fevereiro de 2002. Institui Diretrizes Curriculares Nacionais para a Formação Inicial de Professores para a Educação Básica em Nível Superior, Curso de Licenciatura, de graduação plena. Diário Oficial da União, Brasília, 9 de abril de 2002. Seção 1, p. 31. Disponível em: 〈http://portal.mec.gov.br/cne/arquivos/pdf/rcp01_02.pdf>. Acesso em: 02 jul. 2015.

Ministério da Educação. Conselho Nacional de Educação. Resolução no 7, de 31 de março de 2004. Institui Diretrizes Curriculares Nacionais para os cursos de graduação em Educação Física, em nível superior de graduação plena. Diário Oficial da União, Brasília, 5 de abril de 2004, Seção 1, p. 18. Disponível em: <http://www.cmconsultoria.com.br/legislacao/resolucoes/2004/res_2004_0007_CNE_CES.pd f>. Acesso em: 02 jul. 2015.

CONTRERAS, J. O docente como profissional reflexivo. In: . A autonomia de professores. 2. ed. São Paulo: Cortez, 2012. p.117-146.

FERREIRA, Aurélio Buarque de Holanda. Novo Dicionário Eletrônico Aurélio versão 5.0. Curitiba: Positivo Informática, 2004. 5 CD-ROM.

LIMA, J. G.; BAPTISTA, L. A. Itinerário do conceito de experiência na obra de Walter Benjamin. Princípios Revista de Filosofia, Natal, v. 20, n. 33, p. 449-484, jan./jun. 2013. Disponível em: <http://www.principios.cchla.ufrn.br/arquivos/33P-449-484.pdf>. Acesso em: 21 jul. 2015.

PAGNI, P. A.; GELAMO, R. P. (Org.). Experiência, educação e contemporaneidade. Parte I: experiência e filosofia da educação; infância e acontecimento. Marília: Poiesis, 2010. 
Recebido em: 05/12/2017

Revisado em: 22/01/2018

Aprovado em: 31/01/2018

Endereço para correspondência:

cristiano_mezzaroba@yahoo.com.br

Cristiano Mezzaroba

Universidade Federal de Santa Catarina

Departamento de Educação Física -Campus Universitário,

Trindade 88040-900, Florianópolis, SC 